Check for updates

Cite this: RSC Adv., 2018, 8, 34116

\title{
Synthesis and conductive performance of polyoxometalate acid salt gel electrolytes
}

\author{
Limei $\mathrm{Ai}^{a}{ }^{a}$ Zeqing Wang, ${ }^{a}$ Fengwei $\mathrm{He}^{\mathrm{a}}$ and Qingyin Wu (D) *ab \\ Two vanadium-substituted polyoxometalate acid salt gel electrolytes, $[\mathrm{PyPS}]_{3} \mathrm{H}_{4} \mathrm{SiW}_{9} \mathrm{~V}_{3} \mathrm{O}_{40}$ and \\ [PyPS $]_{5} \mathrm{H}_{2} \mathrm{SiW}_{9} \mathrm{~V}_{3} \mathrm{O}_{40}$, have been synthesized using a 1-(3-sulfonic group) propylpyridine (PyPS) and \\ a Keggin vanadium-substituted heteropoly acid $\mathrm{H}_{7} \mathrm{SiW}_{9} \mathrm{~V}_{3} \mathrm{O}_{40}$ through an ionic self-assembly method, \\ and adjusting the ratio of cation and anion. A substitution effect of the acid salt gel electrolytes has been \\ investigated. Interestingly, when protons of the polyoxometalate acid salt gel electrolytes are substituted, \\ both the conductivity and the phase transformation temperature increase. The fastest conductivity of \\ these gel electrolytes was as high as $2.57 \times 10^{-2} \mathrm{~S} \mathrm{~cm}^{-1}$ at $110{ }^{\circ} \mathrm{C}$.
}

Received 28th August 2018

Accepted 13th September 2018

DOI: $10.1039 / \mathrm{c} 8 \mathrm{ra} 07160 \mathrm{~h}$

rsc.li/rsc-advances

advantages over both a liquid electrolyte and a solid state electrolyte, which makes this new class of materials potential candidates for electrolyte in advanced electrochemical devices. ${ }^{21-25}$ However, many researcher focus on the normal salts of the polyoxometalates ionic liquids (POM-ILs) and there are few articles reported about the acid salts (POM-ASs) of POMILs.

Generally, Keggin-type heteropoly acids have many special characteristics such as stable structure, simple preparation method and high yield. Thus, we chose a Keggin-type vanadium-substituted HPA $\left(\mathrm{H}_{7} \mathrm{SiW}_{9} \mathrm{~V}_{3} \mathrm{O}_{40}\right)$ and the pyridine class with sulfonic group functional compound, 1-(3-sulfonic group) propylpyridine (PyPS) to synthesize a series of POMbased ionic liquids through the ionic self-assembly method. The phase transformation, structure and conductive performance of two POM-ASs compounds were characterized.

rom in the liquid phase at room temperature. The prepa ration of the ionic liquids based on relatively large organic cations and inorganic anions through ionic self-assembly. Ionic liquids have many excellent properties in range of physicochemical, such as thermal stability and electrochemical applications. ${ }^{14-16}$ Many kinds of novel ionic liquids have been synthesized by different cations and anions with ionic selfassembly effect. ${ }^{17,18}$

Recently, many researcher found that the combination of the physical properties of POMs with those of IL salts generated a "chimera", which exhibits a liquid-like property. ${ }^{19}$ These materials show a quasi-solid state at room temperature, and it is changed to a liquid state when being heated to about $100{ }^{\circ} \mathrm{C} .{ }^{20}$ Consequently, the quasi-solid state materials exhibit higher ionic conductivity than that of other solid conductors and have

${ }^{a}$ School of Biomedical and Chemical Engineering, Liaoning Institute of Science and Technology, Benxi 117004, Liaoning, P. R. China. E-mail: qywu@lnist.edu.cn; qywu@zju.edu.cn

${ }^{b}$ Department of Chemistry, Zhejiang University, Hangzhou, 310027, P. R. China

\section{Experimental section}

\subsection{Instrument and reagent}

Elemental analysis was determined by inductively coupled plasma (ICP-MS) analysis on a Shimadzu V-1012 ICP-MS spectrometer. Infrared (IR) spectrum was conducted on a NICOLET NEXUS $470 \mathrm{FT} / \mathrm{IR}$ spectrometer during the wavenumber range $400-4000 \mathrm{~cm}^{-1}$ using $\mathrm{KBr}$ pellet. X-ray powder diffraction (XRD) pattern was conducted on a BRUKER D8 ADVANCE X-ray diffractometer using a $\mathrm{Cu}$ tube at the conditions: at $40 \mathrm{kV}$ and $40 \mathrm{~mA}$ in the range of $2 \theta=4-40^{\circ}$ at a rate of $0.02^{\circ} \cdot \mathrm{s}^{-1}$. The thermal stability of these samples was reported on a SHIMADZU thermal analyzer. Conductivity was measured through a DDS11A conductivity meter using a Shanghai DJS-1 and DJS-10 electrode. The UV absorption spectra were monitored by a Specord TU-1901 UV-vis spectrophotometer.

All the chemicals were of analytical grade and used without further purification. 


\subsection{Synthesis of the POM-ASs}

1-(3-Sulfonic group) propylpyridine (PyPS) was synthesized according to the literature. ${ }^{23} \mathrm{H}_{7} \mathrm{SiW}_{9} \mathrm{~V}_{3} \mathrm{O}_{40}$ was synthesized as follow, $\mathrm{Na}_{10}\left[\alpha-\mathrm{SiW}_{9} \mathrm{O}_{34}\right]$ was synthesized by a method according to recent literature. A $10 \mathrm{~mL}$ aqueous solution of sodium metavanadate $(1.71 \mathrm{~g} \mathrm{NaVO}$ ) was added to a $30 \mathrm{~mL}$ aqueous solution of $\mathrm{Na}_{10}\left[\alpha-\mathrm{SiW}_{9} \mathrm{O}_{34}\right]\left(10 \mathrm{~g} \mathrm{Na}_{10}\left[\alpha-\mathrm{SiW}_{9} \mathrm{O}_{34}\right]\right)$. The mixture was adjusted to $\mathrm{pH}=1.5$. And then, the mixture was added into the $\mathrm{H}^{+}$type cation exchange resin column at room temperature, until the $\mathrm{pH}$ of the mixture is less than 1 . The mixture was dried at $40{ }^{\circ} \mathrm{C}$ and a orange power was obtained.

The pre-synthesized PyPS and $\mathrm{H}_{7} \mathrm{SiW}_{9} \mathrm{~V}_{3} \mathrm{O}_{40}$ were taken in $3: 1$ and $5: 1$ mole ratios to give one mole of $[\mathrm{PyPS}]_{3} \mathrm{H}_{4} \mathrm{SiW}_{9^{-}}$ $\mathrm{V}_{3} \mathrm{O}_{40}$ and $[\mathrm{PyPS}]_{5} \mathrm{H}_{2} \mathrm{SiW}_{9} \mathrm{~V}_{3} \mathrm{O}_{40}$. PyPS was added into an aqueous solution of $\mathrm{H}_{7} \mathrm{SiW}_{9} \mathrm{~V}_{3} \mathrm{O}_{40}$. The mixture was reacted under ultrasound for 10 minutes at room temperature, and then collected bottom layer liquid. The liquid evaporated at room temperature and then the product as oily gel-type was obtained.

\section{Results and discussion}

The detail IR spectra of the compounds at $1100-700 \mathrm{~cm}^{-1}$ is shown in the Fig. 1 and Table 1. As shown in the Fig. 1 and Table 1 , we can clearly find that these feature frequencise, all compounds, fall in the stretching sequence of $\operatorname{vas}\left(\mathrm{Si}-\mathrm{O}_{\mathrm{a}}\right)$, $\operatorname{vas}\left(\mathrm{M}-\mathrm{O}_{\mathrm{d}}\right), \operatorname{vas}\left(\mathrm{M}-\mathrm{O}_{\mathrm{b}}-\mathrm{M}\right)$ and $\operatorname{vas}\left(\mathrm{M}-\mathrm{O}_{\mathrm{c}}-\mathrm{M}\right),(\mathrm{M}=\mathrm{W}, \mathrm{V})$, which is referred to POM character bands at $1100-700 \mathrm{~cm}^{-1}$. We also find the shift of characteristic peaks of POM-ASs in the Fig. 1 and Table 1 when compared with POM. This phenomenon can be explained by the vibrations frequency change result in the

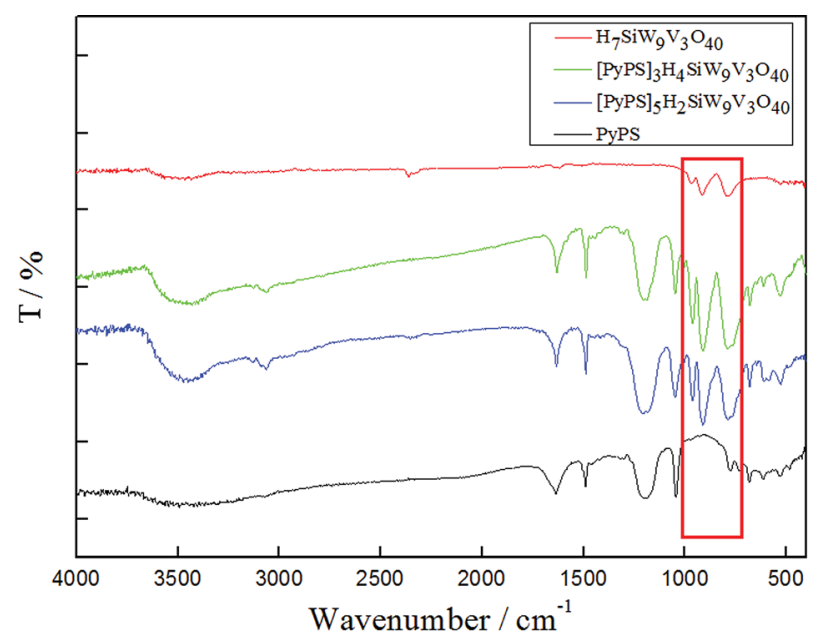

Fig. 1 IR spectra of the compounds.

Table 1 The detail IR spectra of compounds at $1100-700 \mathrm{~cm}^{-1}$

\begin{tabular}{llll}
\hline Vibrations $/ \mathrm{cm}^{-1}$ & $\mathrm{SiW}_{9} \mathrm{~V}_{3}$ & {$[\mathrm{PyPS}]_{3} \mathrm{H}_{4} \mathrm{SiW}_{9} \mathrm{~V}_{3}$} & {$[\mathrm{PyPS}]_{5} \mathrm{H}_{2} \mathrm{SiW}_{9} \mathrm{~V}_{3}$} \\
\hline $\mathrm{M}-\mathrm{O}_{\mathrm{d}}$ stretching & 970 & 960 & 962 \\
Si- $\mathrm{O}_{\mathrm{a}}$ stretching & 914 & 911 & 908 \\
${\mathrm{M}-\mathrm{O}_{\mathrm{c}}-\mathrm{M} \text { stretching }}^{785}$ & 790 & 788
\end{tabular}

influence of the anion-anion interactions among polyoxoanions. ${ }^{26,27}$ In spite of the shift of characteristic peaks of POM-ASs, the peaks still exists, which can find at a red zone in the Fig. 1. The result infer that these compounds still maintain POM structure without decomposition, when PyPS added.

The POM in non-reduced state is generally characterized by charge transfer bands of oxygen-to-metal, which can be observed by UV-vis spectrophotometer in the UV region below $400 \mathrm{~nm}$. The UV absorption spectrum of the compounds is shown in the Fig. 2. As shown in the Fig. 2, we can find that the absorption bands of $\mathrm{H}_{7} \mathrm{SiW}_{9} \mathrm{~V}_{3} \mathrm{O}_{40}$, [PyPS $]_{3} \mathrm{H}_{4} \mathrm{SiW}_{9} \mathrm{~V}_{3} \mathrm{O}_{40}$ and [PyPS $]_{5} \mathrm{H}_{2} \mathrm{SiW}_{9} \mathrm{~V}_{3} \mathrm{O}_{40}$ appear at about $260 \mathrm{~nm}, 259 \mathrm{~nm}, 260 \mathrm{~nm}$, respectively. The absorption spectrum of POM-ILs display a moderately intense peak nearly $259 \mathrm{~nm}(\mathrm{O}-\mathrm{M})$ and the peak is blue-shifted from $260 \mathrm{~nm}$ which is referred to the pure POM. ${ }^{28}$ This phenomenon can provide an evidence for intermolecular interactions between PyPS cations and Keggin-type anion units.

Wide-angle XRD patterns of POM and POM-ASs are shown in the Fig. 4. The intensity is very strong peaks in the large region of the XRD patterns of $\mathrm{H}_{7} \mathrm{SiW}_{9} \mathrm{~V}_{3} \mathrm{O}_{40}$. The Keggin-type of the polyoxometalates which exhibited typical peaks in the range of $2 \theta=7-11^{\circ}$ in the XRD patterns was found. From that phenomenon, it is clear that the POM compound was successfully prepared. Furthermore, we also found a broad diffraction peaks in the region of $2 \theta=20-35^{\circ}$ of POM-ASs, which indicates the distinction between the POM-ASs and their parent HPA. ${ }^{29}$ $[\mathrm{PyPS}]_{3} \mathrm{H}_{4} \mathrm{SiW}_{9} \mathrm{~V}_{3} \mathrm{O}_{40}$ and $[\mathrm{PyPS}]_{5} \mathrm{H}_{2} \mathrm{SiW}_{9} \mathrm{~V}_{3} \mathrm{O}_{40}$ present similar $\mathrm{XRD}$ pattern. This phenomenon infers that the parent HPA is changes into amorphous structure after the acidic protons (PyPS) were added.

These POM-ASs exhibit a characteristic of reversible gelliquid phase transformation. Fig. 5 shows the POM-ASs phase transform between gel state and liquid state at $100{ }^{\circ} \mathrm{C}$. Since the weak connection among PyPS cation, POM anion and protons, the gel state of POM-ASs exhibit amorphous state, which can be proved by XRD patterns, and the schematic is shown in Fig. 3.

The variation of the conductivity of these compounds can be observed with heating. The results of variation of conductivity show in the Fig. 6. As shown in the Fig. 6, it can find that there is

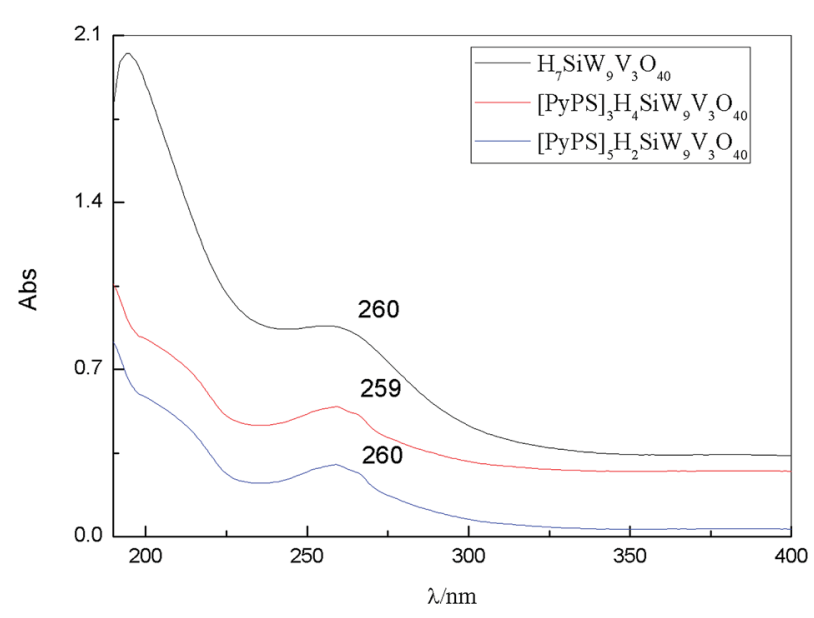

Fig. 2 The UV absorption spectra of the HPA and POM-ASs. 

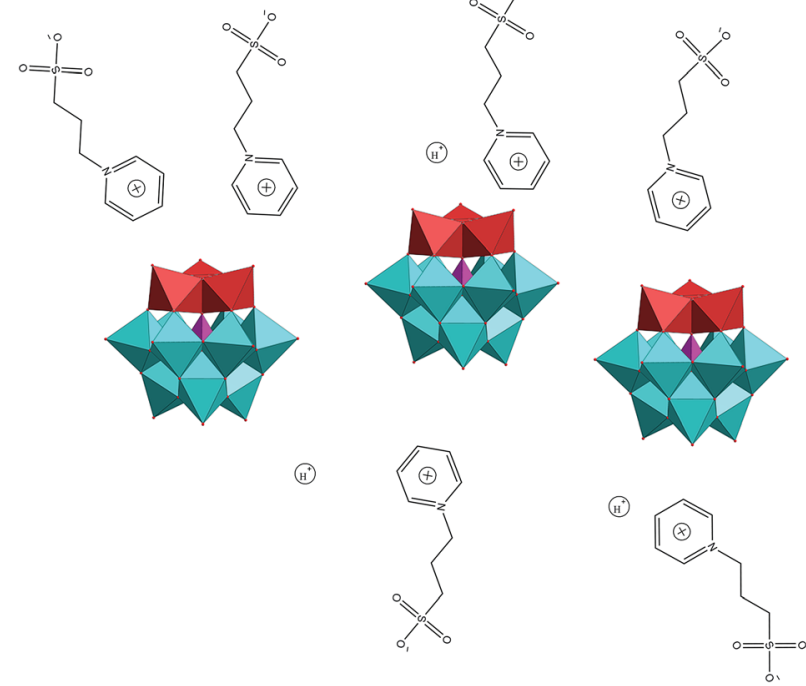

Fig. 3 Schematic illustration of potential weak connections in these compounds among PyPS, protons and POM anion.

a broad endothermic peak at about $85{ }^{\circ} \mathrm{C}$ for $[\mathrm{PyPS}]_{3} \mathrm{H}_{4} \mathrm{SiW}_{9}{ }^{-}$ $\mathrm{V}_{3} \mathrm{O}_{40}$ and at about $70{ }^{\circ} \mathrm{C}$ for $[\mathrm{PyPS}]_{5} \mathrm{H}_{2} \mathrm{SiW}_{9} \mathrm{~V}_{3} \mathrm{O}_{40}$. That phenomenon can be attributed to a phase transformation from a solid gel phase to an isotropic liquid phase. ${ }^{30}$ It can also find that the conductivity of these compounds increase with heating, especially at the time that these compounds at the temperature

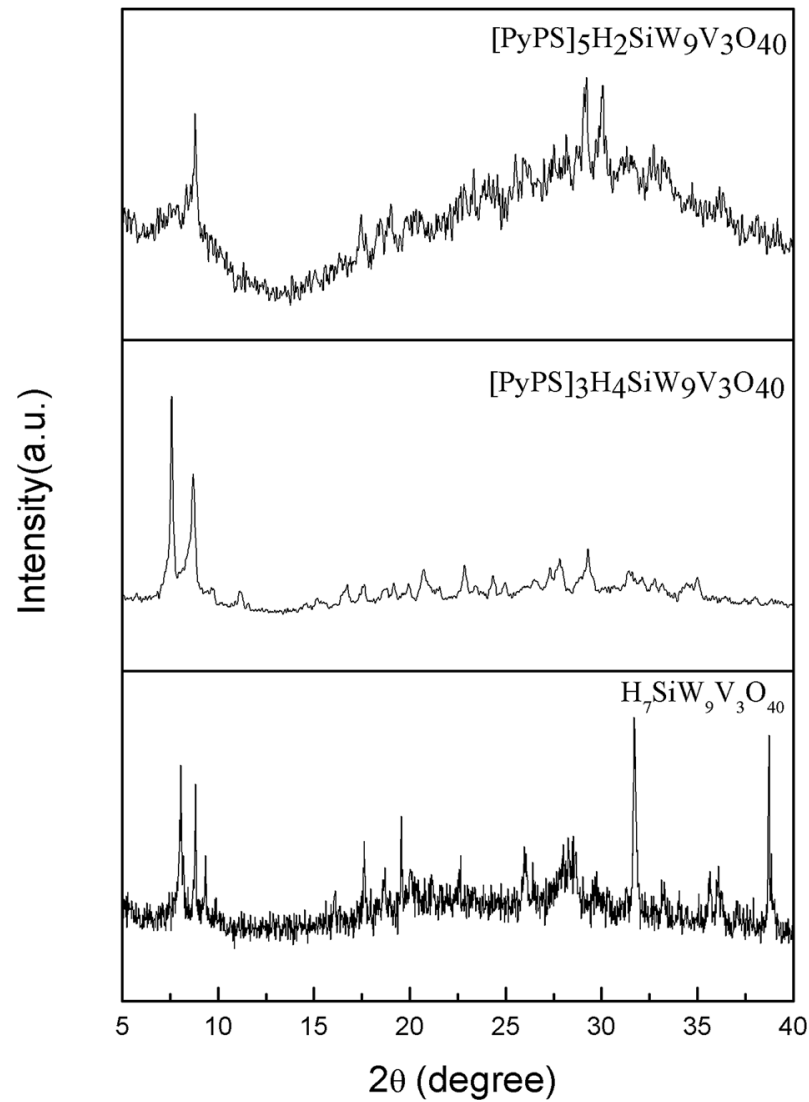

Fig. 4 Wide-angle XRD patterns of the HPA and POM-ASs.

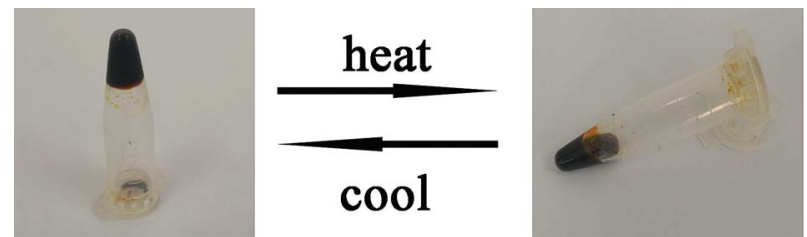

Fig. 5 Photographs of the $[\mathrm{PyPS}]_{3} \mathrm{H}_{4} \mathrm{SiW}_{9} \mathrm{~V}_{3} \mathrm{O}_{40}$ reversible gel-liquid phase transformation at room temperature and $100{ }^{\circ} \mathrm{C}$.

a

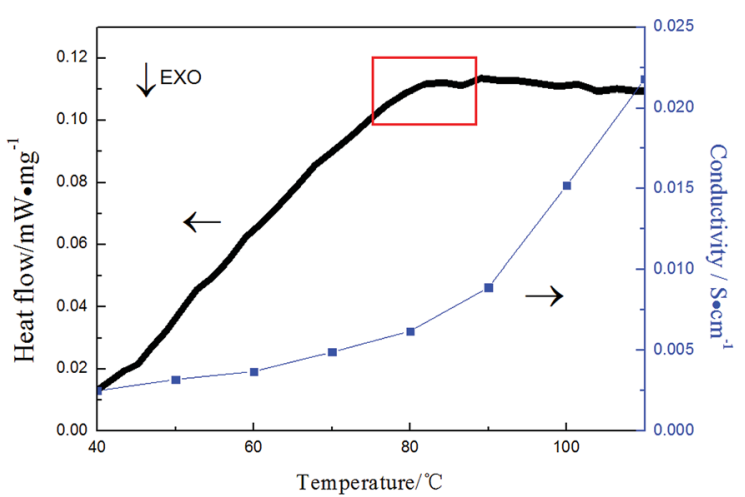

$b$

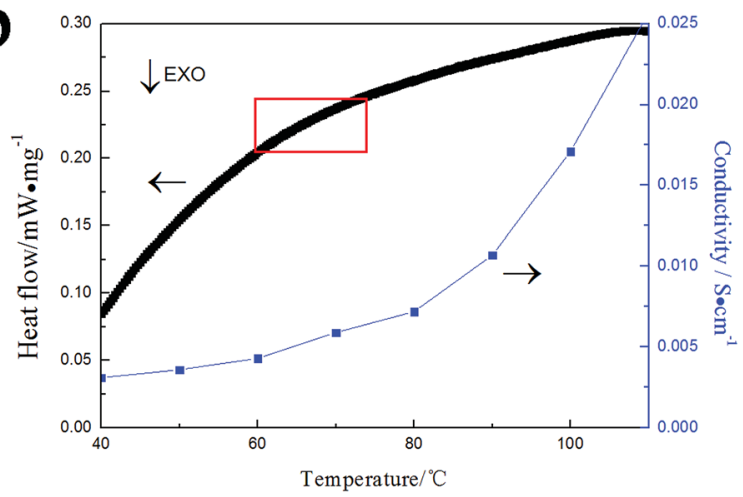

Fig. 6 Conductivity-temperature and heat flow curves of (a) $[\mathrm{PyPS}]_{3} \mathrm{H}_{4} \mathrm{SiW}_{9} \mathrm{~V}_{3} \mathrm{O}_{40}$ and (b) $[\mathrm{PyPS}]_{5} \mathrm{H}_{2} \mathrm{SiW}_{9} \mathrm{~V}_{3} \mathrm{O}_{40}$.

of phase transformation from gel to liquid, the phenomenon of increasing conductivity is obvious. Concretely, at $110{ }^{\circ} \mathrm{C}$ the conductivity of $[\mathrm{PyPS}]_{3} \mathrm{H}_{4} \mathrm{SiW}_{9} \mathrm{~V}_{3} \mathrm{O}_{40}$ and $[\mathrm{PyPS}]_{5} \mathrm{H}_{2} \mathrm{SiW}_{9} \mathrm{~V}_{3} \mathrm{O}_{40}$ is $2.57 \times 10^{-2} \mathrm{~S} \mathrm{~cm}^{-1}$ and $2.18 \times 10^{-2} \mathrm{~S} \mathrm{~cm}^{-1}$, respectively. The phenomenon can be resulted in an increase in the migration of particles in the compound.

Fig. 7 shows conductivity of different amount of PyPS substitution at different temperature. Obviously, when the number of protons in the compound increase, the conductivity of these compounds enhance accordingly. This phenomenon can be explained as that the protons in the compounds migrate much faster than PyPS. Thus it is found that the higher conductivity can result from more protons in the compound. Additionally, when many protons have substituted the PyPS, the conductivity of the compounds also increase. So it is infer that more protons in the compounds will result in higher conductivity. Furthermore, this result also can be confirmed by conductive activation energy. ${ }^{31,32}$ 


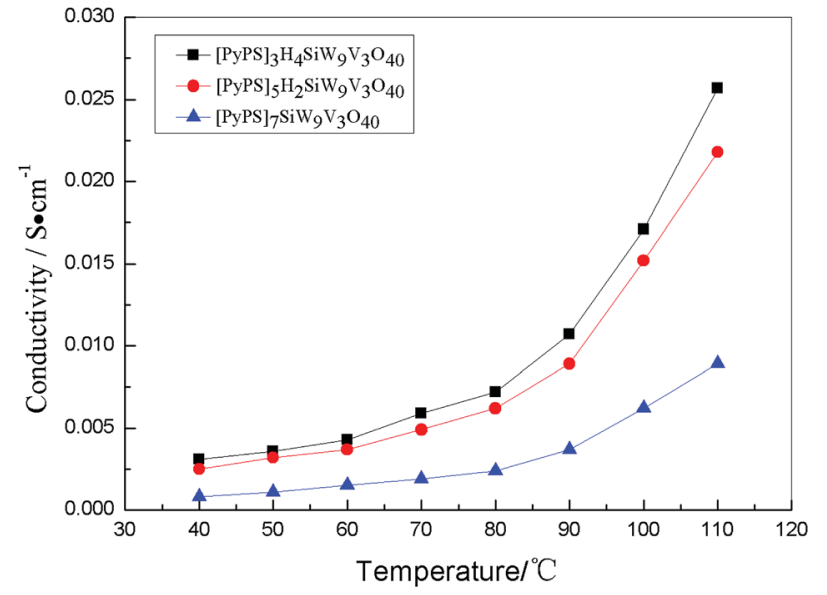

Fig. 7 Conductivity-temperature plots of $[\mathrm{PyPS}]_{3} \mathrm{H}_{4} \mathrm{SiW}_{9} \mathrm{~V}_{3} \mathrm{O}_{40}$, $[P y P S]_{5} \mathrm{H}_{2} \mathrm{SiW}_{9} \mathrm{~V}_{3} \mathrm{O}_{40}$ and $[\mathrm{PyPS}]_{7} \mathrm{SiW}_{9} \mathrm{~V}_{3} \mathrm{O}_{40}$.

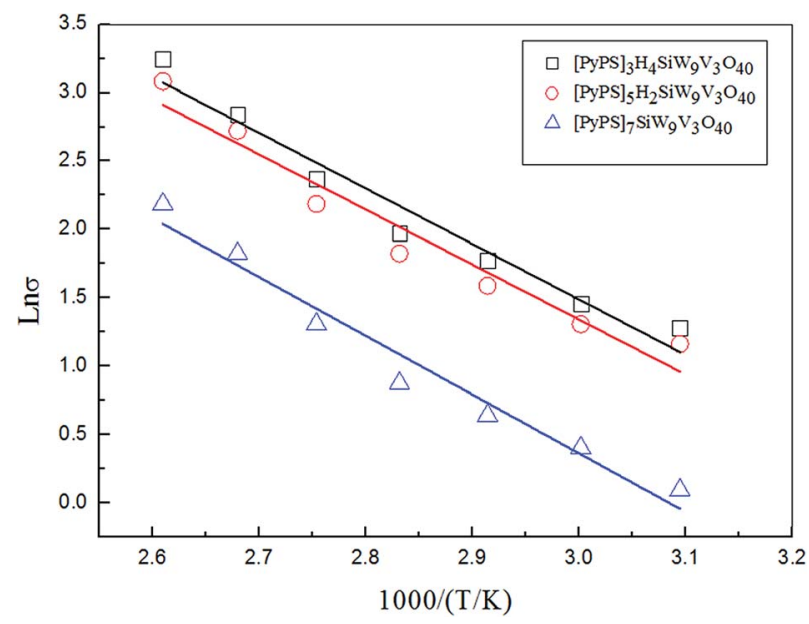

Fig. 8 The conductive Arrhenius plots of $[\mathrm{PyPS}]_{3} \mathrm{H}_{4} \mathrm{SiW}_{9} \mathrm{~V}_{3} \mathrm{O}_{40}$, $[\text { PyPS }]_{5} \mathrm{H}_{2} \mathrm{SiW}_{9} \mathrm{~V}_{3} \mathrm{O}_{40}$ and [PyPS] $\mathrm{SiW}_{9} \mathrm{~V}_{3} \mathrm{O}_{40}$ at the same condition.

The conductive activation energy $E_{\mathrm{a}}$ can be evaluated as follow

$$
\sigma=\sigma_{0} \exp \left(\frac{-E_{\mathrm{a}}}{R T}\right)
$$

where $\sigma$ is conductive, $\sigma_{0}$ is the pre-exponential factor, $E_{\mathrm{a}}$ is the conductive activation energy, $R$ is the gas constant and $T$ is the absolute temperature. Fig. 8 shows the conductive Arrhenius plots of $[\mathrm{PyPS}]_{3} \mathrm{H}_{4} \mathrm{SiW}_{9} \mathrm{~V}_{3} \mathrm{O}_{40},[\mathrm{PyPS}]_{5} \mathrm{H}_{2} \mathrm{SiW}_{9} \mathrm{~V}_{3} \mathrm{O}_{40}$ and $[\mathrm{PyPS}]_{7^{-}}$ $\mathrm{SiW}_{9} \mathrm{~V}_{3} \mathrm{O}_{40}$ at the same condition. The values of $E_{\mathrm{a}}$ of these compounds can be obtained by linear fit and the values of $E_{\mathrm{a}}$ for $[\mathrm{PyPS}]_{3} \mathrm{H}_{4} \mathrm{SiW}_{9} \mathrm{~V}_{3} \mathrm{O}_{40},[\mathrm{PyPS}]_{5} \mathrm{H}_{2} \mathrm{SiW}_{9} \mathrm{~V}_{3} \mathrm{O}_{40}$ and $[\mathrm{PyPS}]_{7} \mathrm{SiW}_{9} \mathrm{~V}_{3^{-}}$ $\mathrm{O}_{40}$ is $33.4 \mathrm{~kJ} \mathrm{~mol}^{-1}, 33.7 \mathrm{~kJ} \mathrm{~mol}^{-1}$ and $35.7 \mathrm{~kJ} \mathrm{~mol}^{-1}$, respectively. In this case, it is found that number of protons have an obvious influence on conductivity of the compounds.

\section{Conclusions}

In this paper, we have reported two vanadium-substituted polyoxometalate acid salts gel electrolytes, $[\mathrm{PyPS}]_{3} \mathrm{H}_{4} \mathrm{SiW}_{9} \mathrm{~V}_{3} \mathrm{O}_{40}$ and $[\mathrm{PyPS}]_{5} \mathrm{H}_{2} \mathrm{SiW}_{9} \mathrm{~V}_{3} \mathrm{O}_{40}$. These electrolytes exhibit reversible gel-liquid phase transformation. A relationship among the conductivity, substituted protons and temperature can be observed by heat flow and conductivity plots. The results indicate that the conductivity and phase transformation temperature improve with increasing the number of protons in the compounds. Thus these materials maybe provide both liquid state electrolytes and solid state electrolytes for supercapacitors.

\section{Conflicts of interest}

There are no conflicts to declare.

\section{Acknowledgements}

This work was supported by the Liaoning Provincial Natural Science Foundation of China (201602404), the Zhejiang Provincial Natural Science Foundation of China (LY18B010001) and the Scientific Research Foundation of Liaoning Institute of Science and Technology (RXYJ2015001).

\section{References}

1 M. Shiddiq, D. Komijani, D. Yan, A. Gaitaariño, E. Coronado and S. Hill, Nature, 2016, 531, 348-351.

2 Z. Chen, W. B. Bu, D. L. Ni, C. J. Zuo, C. Chao, Q. Li, L. L. Zhang, W. Zheng and J. L. Shi, J. Am. Chem. Soc., 2016, 138, 8156-8164.

3 A. Rubinstein, P. Jiménezlozanao, J. J. Carbó, J. M. Poblet and R. Neumann, J. Am. Chem. Soc., 2014, 136, 10941-10948.

4 T. Yoshida, T. Murayama, N. Sakaguchi, M. Okumura, T. Ishida and M. Haruta, Angew. Chem., Int. Ed., 2018, 57, 1523-1527.

5 J. J. Chen, M. D. Symes, S. C. Fan, M. S. Zheng, H. N. Miras, Q. F. Dong and L. Cronin, Adv. Mater., 2017, 27, 4649-4654.

6 Y. W. Liu, S. M. Liu, X. Y. Lai, J. Miao, D. F. He, N. Li, F. Luo, Z. Shi and S. X. Liu, Adv. Funct. Mater., 2015, 25, 4480-4485.

7 X. Tong, N. Q. Tian, W. Wu, W. M Zhu, Q. Y. Wu, F. H. Cao, W. F. Yan and A. B. Yaroslavtsev, J. Phys. Chem. C, 2013, 117, 3258-3263.

8 J. J. Chen, J. C. Ye, X. G. Zhang, M. D. Symes, S. C. Fan, D. L. Long, M. S. Zheng, D. Y. Wu, L. Cronin and Q. F. Dong, Adv. Energy Mater., 2018, 8, 1701021.

9 M. H. Yang, B. G. Choi, S. C. Jung, Y. K. Han, Y. S. Huh and S. B. Lee, Adv. Funct. Mater., 2015, 24, 7301-7309.

10 H. Gao, A. Virya and K. Lian, J. Mater. Chem. A, 2015, 3, 21511-21517.

11 M. Tountas, Y. Topal, A. Verykios, A. Soultati, A. Kaltzoglou, T. A. Papadopoulos, F. Auras, K. Seintis, M. Fakis and L. C. Palilis, J. Mater. Chem. C, 2018, 6, 1459-1469.

12 X. F. Wu, W. Wu, Q. Y. Wu and W. F. Yan, Langmuir, 2017, 33, 4242-4249.

13 W. B. Kim, T. Voitl, G. J. Rodriguezrivera and J. A. Dumesic, Science, 2004, 305, 1280-1283.

14 W. L. Zhou, J. Peng, Z. Y. Zhang, Z. Y. Shi, S. U. Khan and H. S. Liu, RSC Adv., 2015, 5, 35753-35759. 
15 E. Rafiee, S. Eavani, X. Cai, X. F. Wu, R. S. Anaredy and S. K. Shaw, RSC Adv., 2016, 6, 46433-46466.

16 R. Hayes, G. G. Warr and R. Atkin, Chem. Rev., 2015, 115, 6357-6426.

17 E. Elfassy, Y. Mastai, D. Pontoni and M. Deutsch, Langmuir, 2016, 32, 3164-3173.

18 Q. Y. Wu, X. Tong and X. F. Wu, J. Xuzhou Inst. Technol., Nat. Sci. Ed., 2011, 26, 1-8.

19 J. Azizullah, M. Al-Rashida, A. Haider, U. Kortz, S. A. Joshi and J. Iqbal, ChemistrySelect, 2018, 3, 1472-1479.

20 A. B. Bourlinos, K. Raman, R. Herrera, Q. Zhang, L. A. Archer and E. P. Giannelis, J. Am. Chem. Soc., 2004, 126, 1535815359.

21 S. Akbani, M. T. Hamed Mosavian, F. Moosavi and A. Ahmadpour, RSC Adv., 2017, 7, 44537-44546.

22 A. R. Neale, C. Schütter, P. Wilde, P. Goodrich, C. Hardacre, S. Passerini, A. Balducci and J. Jacquemin, J. Chem. Eng. Data, 2017, 62, 376-390.

23 Y. Leng, J. Wang, D. R. Zhu, X. Q. Ren, H. Q. Ge and L. Shen, Angew. Chem., Int. Ed., 2010, 48, 168-171.
24 X. F. Wu, X. H. Zhou, Q. Y. Wu and W. F. Yan, New J. Chem., 2016, 40, 7923-7927.

25 Y. Y. Li, X. F. Wu, Q. Y. Wu, H. Ding and W. F. Yan, Dalton Trans., 2014, 43, 13591-13595.

26 Z. K. Zhao, Y. T. Dai, T. Bao, R. Z. Li and G. R. Wang, J. Catal., 2012, 288, 44-53.

27 T. P Huang, N. Q. Tian, Q. Y. Wu and W. F. Yan, Soft Matter, 2015, 11, 4481-4486.

28 X. F. Wu, X. Tong, Q. Y. Wu, H. Ding and W. F. Yan, J. Mater. Chem. A, 2014, 2, 5780-5784.

29 Z. R. Xie, Q. Y. Wu and L. M. Ai, Funct. Mater. Lett., 2018, 11, 1850059.

30 T. L. Greaves and C. J. Drummond, Chem. Rev., 2008, 108, 206-237.

31 M. A. Hickner, H. Ghassemi, S. K. Yu, B. R. Einsla and J. E. Mcgrath, Chem. Rev., 2004, 104, 4587-4611.

32 Z. R. Xie, H. Wu, Q. Y. Wu and L. M. Ai, $R S C A d v ., 2018,8$, 13984-13988. 